\title{
OUTRAS "PEDAGOGIAS" PARA A EDUCAÇÃO EM TEMPO INTEGRAL
}

\section{OTHER "PEDAGOGIES" FOR FULL TIME EDUCATION}

\author{
M. B. SIRINO ${ }^{1, *}$, A. V. FERREIRA ${ }^{2}$ e P. F. MOTA ${ }^{3}$ \\ 1 Universidade Castelo Branco, Brasil. \\ 2 Universidade do Estado do Rio de Janeiro, Brasil. \\ ${ }^{3}$ Universidade Federal do Estado do Rio de Janeiro, Brasil.
}

\author{
ARTICLEINFO \\ Article history: \\ Received 2018-07-02 \\ Accepted 2018-08-17 \\ Available online 2018-08-31 \\ ${ }^{*}$ Autor correspondente: \\ E-mail:pedagogomarcio@gmail.com
}

Palavras-chave: Educação em Tempo Integral. Educação Integral. Paulo Freire. Pedagogia da Convivência.

Keywords: Full-Time. Integral Education. Paulo Freire. Pedagogy of Coexistence.

RESUMO. O presente artigo tem por objetivo apresentar uma reflexão teórica sobre a possibilidade de materialização da Educação em Tempo Integral com o aporte teórico de novas formas pedagógicas para organizá-la. A partir da compreensão de Paiva (2015) sobre as obras de Paulo Freire no que tange à construção de outras "Pedagogias" (p. 123), trazemos, nesta produção, quatro possibilidades de organização da jornada escolar dos educandos, na perspectiva de se alcançar uma educação, efetivamente, integral, a saber: a Pedagogia do Oprimido (FREIRE, 1987); a Pedagogia da Autonomia (FREIRE, 1996); a Pedagogia da Convivência (JARES, 2008) e a Pedagogia da Hospitalidade (BAPTISTA, 2012). Com uma perspectiva metodológica de cunho qualitativo, buscamos, por meio da pesquisa bibliográfica, evidenciar a necessidade de potencializar as multiplicidades de Pedagogias que possibilitem a construção de um cotidiano escolar e/ou não escolar - em tempo integral diferenciado onde os valores da cidadania, trabalho e convivência sejam elementos integralizadores do processo educacional.

ABSTRACT. The present article aims to present a theoretical reflection about the possibility of materialization of Education in Integral Time with the theoretical contribution of new pedagogical forms to organize it. From Paiva's (2015) understanding of Paulo Freire's works on the construction of other "Pedagogies" (p. 123), we present in this production four possibilities of organizing the students' school day, in the perspective of to achieve an education that is truly comprehensive, namely: Pedagogy of the Oppressed (FREIRE, 1987); the Pedagogy of Autonomy (FREIRE, 1996); the Pedagogy of Convivencia (JARES, 2008) and the Pedagogy of Hospitality (BAPTISTA, 2012). With a qualitative methodological perspective, we seek, through bibliographical research, to highlight the need to enhance the multiplicities of Pedagogies that allow the construction of a differentiated full time school - and/or non-school - daily life where the values of citizenship, work and coexistence are integral elements of the educational process. 


\section{Introdução: uma contextualização necessária}

O Grupo de Estudos, Pesquisas e Extensão (GEPE) Fora da Sala de Aula - da Universidade do Estado do Rio de Janeiro (UERJ), campus São Gonçalo/RJ, devidamente registrado no SR3/no4955 da UERJ e intitulado como 'Fora da Sala de Aula: Formações, Representações e Práticas educativas não escolares e/ou extracurriculares no município de São Gonçalo', desde 2016 vem realizando estudos, pesquisas e atividades de extensão no campo da Educação Social e da Pedagogia Social em busca de novas formas de práticas pedagógicas dentro e fora do ambiente escolar.

Ao longo desse tempo, diversas atividades vêm sendo desenvolvidas no GEPE, a saber: Grupo de Estudo (onde textos que fundamentam o campo teórico da Pedagogia Social e da Psicologia da Educação são discutidos entre os participantes); Oficine Social (no qual é exibido um vídeo seguido de uma roda de debates entre os presentes); Cursos de Extensão, na modalidade a distância, para a formação dos educadores sociais e profissionais da área da educação com temáticas voltadas para a Educação Social, Pedagogia Social e Psicologia da Educação; Participação dos pesquisadores integrantes do GEPE em diferentes eventos no campo da educação fora da Universidade (Secretarias de Educação e outros cursos) e, a realização anual da Jornada de Educação Não Escolar e Pedagogia Social (JENEPS) na Faculdade de Formação de Professores da Universidade do Estado do Rio de Janeiro (UERJFFP), em São Gonçalo.

Destacamos que, nos diversos momentos formativos promovidos por este grupo, vimos dialogando sobre práticas educativas - dentro e/ou fora da sala de aula - que contribuam para uma educação mais completa aos sujeitos inseridos no processo de ensinoaprendizagem. A partir da leitura da obra "Caminhos do Educador Social no Brasil", de Jacyara Paiva, e em uma perspectiva de reorganizar de maneira nova, antigos conceitos pedagógicos, o grupo viu a necessidade de se pensar em 'Pedagogias' que, porventura, venham a produzir novos sentidos à pratica educativa. Neste bojo, atrelamos sua materialização numa escola de Educação em Tempo Integral - visto que, com mais tempo na escola, aumenta-se a oportunidade de aprendizagem e a promoção de experiências educativas diferenciadas que, certamente, muito têm a contribuir para o desenvolvimento dos educandos.

Este exercício de reflexão bibliográfica pode ser percebido na experiência socializada por Sirino (2017) referente ao projeto "Roda do Abraço" desenvolvido numa escola de Educação em Tempo Integral no município Angra dos Reis/RJ. O autor faz uma articulação entre esse projeto com a possibilidade de fortalecimento dos laços humanos entre os sujeitos desse cotidiano. Neste caminhar, Cavaliere e Coelho (2017) apresentam - sobre essa experiência educativa - que o artigo do Prof. Marcio Sirino revela o entendimento do tempo integral, na escola, como: 
Uma formação mais completa que, entre outras possibilidades precisa incorporar, não somente o que tradicionalmente denominamos como 'componentes curriculares' regulares, mas também outros conhecimentos e saberes que incluem, por exemplo, a subjetividade e os valores humanos ( $p$. 18).

A experiência sinalizada acima é um exemplo de rompimento com a visão tradicional de escola e, ainda, de possibilidade de construção de outras 'Pedagogias' - no cotidiano escolar de uma unidade de Educação em Tempo Integral, que prima pela formação integral de seus educandos - e de promoção de uma educação de qualidade.

Esta elaboração teórica busca trazer, em sua estrutura, aportes conceituais sobre a temática da Educação em Tempo Integral e, em seguida, seções sintetizadas com os principais apontamentos de cada uma das 'Pedagogias' que selecionamos como importantes para essa possível construção de diálogo e novas perspectivas de práticas educacionais.

\section{Educação em Tempo Integral}

Em diferentes estudos sobre a Educação em Tempo Integral ou sobre a utilização do próprio tempo de forma qualitativa no cotidiano escolar, identificamos uma diversidade de perspectivas inerentes a esta ampliação da jornada escolar dos educandos/ampliação das oportunidades de sua aprendizagem, quer seja pelo reconhecimento da dívida histórica para com os alunos das classes populares; pela compreensão de que a promoção de uma educação de melhor qualidade exige um maior tempo para a oferta de novas oportunidades educacionais; pela necessidade de proteger os educandos inseridos em espaços de risco social ou, ainda, pela junção de todos esses fatores e de muitos outros que se desdobram ao longo do processo.

Para ampliarmos o repertório conceitual sobre a Educação em Tempo Integral, trazemos a compreensão de Moll (2010) apud Leclerc, e Moll (2012), que pontua o tempo integral em dois sentidos - "restrito" e "amplo":

\footnotetext{
Escola de tempo integral. Em sentido restrito refere-se à organização escolar na qual o tempo de permanência dos estudantes se amplia para além do turno escolar, também denominada, em alguns países, como jornada escolar completa. Em sentido amplo, abrange o debate da educação integral consideradas as necessidades formativas nos campos cognitivo, estético, ético, lúdico, físico-motor, espiritual, entre outros - no qual a categoria "tempo escolar" reveste-se de relevante significado tanto em relação a sua ampliação, quanto em relação à necessidade de sua reinvenção no cotidiano escolar (p. 96).
}

Partindo da percepção de que a construção da educação em 'tempo integral' é abordada pela autora com a aglutinação de dois sentidos distintos - ampliação da jornada 
escolar e as necessidades formativas em diferentes dimensões, problematizamos a tendência 'contemporânea', de amalgamar conceitos e a eles atribuir novos significados.

Encontramos, nesta perspectiva, aspectos que dialogam com os pressupostos de Gadotti (2009), uma vez que o mesmo percebe que "a educação se dá em tempo integral, na escola, na família, na rua, em todos os turnos, de manhã, de tarde, de noite, no cotidiano de todas as nossas experiências e vivências" (p. 21).

Neste bojo - de uma educação que ocorra em todos os espaços e territórios questionamos o papel social da escola nesta contemporaneidade, pois partimos da compreensão de que a função principal da educação escolar seja a apropriação dos conhecimentos socioistoricamente construídos. Mas, esta visão mais atual - em que a escola se configura como mais uma das instituições que promovem formação às crianças e aos adolescentes - qualifica ou desprestigia a atuação da educação escolar?

Neste sentido, somos confrontados com Frabboni (2001, p. 34) ao nos afirmar que essa articulação entre o território e a unidade escolar se constitui numa "equação possível". Concordamos que a educação se dá em todos os tempos e espaços e que esta integração seja, ainda, possível e necessária. No entanto, reforçamos que, a nosso ver - enquanto política pública - a proposta de Educação em Tempo Integral, mesmo que por meio de atividades dentro ou fora da escola, deve estar sob a responsabilidade da mesma. Ângulo este que podemos encontrar, por exemplo, nas afirmações de Menezes (2009):

O aumento do tempo com vistas à formação integral do indivíduo deve constituir-se na ampliação do tempo escolar, aqui considerado como o tempo que a criança está sob a responsabilidade da escola, em atividades que podem ocorrer de forma intra ou extra-escolar. Aspectos estes que evidenciam a centralidade da escola no processo ensino-aprendizagem ( $p$. 85).

Se, porventura, no contexto brasileiro, o tempo escolar corresponde ao "tempo em que a criança está sob responsabilidade da escola", por outro lado, em outros países, o conceito de "tempo escolar" possui outras interpretações. Nesta direção, trazemos as contribuições de Pereyra (1992), uma vez que, em estudos sobre a "jornada e os tempos escolares numa nova época", apresentou três casos de ampliação da jornada escolar europeia, a pontuar: Alemanha, Dinamarca e Itália. Convém contextualizar que esta ampliação é realizada no espaço físico da escola, mas não se configura numa ação escolar. As atividades propostas, assim como alimentação, são pagas e se estendem a apenas alguns alunos, de forma a alcançar a mesma jornada de trabalho de seus responsáveis, objetivando diminuir a influência negativa sobre a educação dos alunos e também a precariedade cultural, como podemos observar em Pereyra apud Maurício (2014): 
A prolongação do tempo na escola, com jornada estendida, a toda manhã e tarde, serviria, sobretudo, para diminuir, o maior tempo possível, a influência negativa sobre a educação dos alunos e também a precariedade cultural de sua família e seu bairro (p. 43).

Inferimos que - nesta compreensão de ampliação da jornada escolar - o tempo integral é atrelado a uma visão de assistência, na qual o aumento da carga horária está associado à necessidade que os pais possuem de deixarem seus filhos num local de segurança e proteção.

Entretanto, resgatando a discussão acerca da valorização da centralidade da escola na educação, acreditamos que a promoção de uma Educação em Tempo Integral eficaz exige "saberes necessários à prática educativa", como previa Freire (1996), saberes esses que problematizem o papel da educação no cenário atual, oportunizem análises críticas acerca da função social da escola pública, possibilitem refletir sobre o estabelecimento de parcerias e inclusão de outros agentes na prática pedagógica e, ainda, dentre muitos outros aspectos, auxiliem na construção do trabalho docente, pois, segundo Hargreaves (1992) "el tiempo es el elemento más importante en la estructuración del trabajo del profesor" (p. 31).

Desse modo, partindo da centralidade da escola, acreditamos que com uma Educação em Tempo Integral, esses saberes serão postos em prática e a luta em prol de uma educação que vise minimizar as desigualdades educacionais e sociais, bem como desenvolver o educando em diferentes dimensões formadoras será, enfim, materializada. Para tanto, ressaltamos a necessidade da ampliação da jornada escolar para uma Educação em Tempo Integral, como nos afirma Maurício (2009):

É necessário tempo de permanência na escola para que a criança das classes populares tenha igualdade de oportunidade que as crianças de classe média têm, em espaços variados e ao longo do dia inteiro, com acesso a linguagens e circunstâncias diversas. É necessário tempo para adquirir hábitos, valores, conhecimentos para o exercício da cidadania numa sociedade complexa como a brasileira do século XXI (p. 55).

Esta perspectiva dialoga com a visão de Educação em Tempo Integral em que nos fundamentamos, por reconhecermos que, para a promoção dessa formação humana mais completa para o educando, carecemos de mais tempo a fim de que ele se perceba, reflita, critique, tenha novas possibilidades de ser, pensar, fazer e querer na sociedade em que está inserido. Desse modo, trazemos, novamente, os pressupostos de Maurício (2009), que nos faz perceber a importância do tempo na promoção de uma educação de qualidade:

É necessário tempo para escovar dentes; é necessário tempo para fazer leitura crítica das imagens veiculadas pela televisão; é necessário tempo para praticar valores democráticos, na educação física, na hora da refeição, nas discussões em sala de aula (p. 55). 
Como podemos perceber, a ampliação da jornada escolar dos educandos para uma Educação em Tempo Integral está atrelada a diversas concepções. Cavaliere (2007) afirma que "o tempo de escola é sempre função de diferentes interesses e forças que sobre ele atuam" (p. 1018). Neste ensejo, apresentamos os pressupostos de Cavaliere (2007) acerca dessa questão, enquanto síntese das compreensões existentes e abordadas, no que tange às "diferentes visões de escola de tempo integral que podem levar a projetos com objetivos até mesmo antagônicos" (p. 1028).

A autora sistematiza-os em quatro visões, a saber: assistencialista; autoritária; democrática e multissetorial. Sinalizamos, abaixo, as especificidades de cada uma:

Visão Assistencialista- "vê a escola de tempo integral como uma escola para desprivilegiados, que deve suprir deficiências gerais da formação dos alunos".

Visão Autoritária- "a escola de tempo integral é uma espécie de instituição de prevenção do crime".

Visão Democrática- "o tempo integral seria um meio de proporcionar uma educação mais efetiva do ponto de vista cultural, com o aprofundamento dos conhecimentos, do espírito crítico e das vivências democráticas".

Visão Multissetorial- "a educação pode e deve se fazer fora da escola. tempo integral não precisa estar centralizado a uma instituição".

(CAVALIERE, 2007, p. 1028 e 1029)

Partindo desses esclarecimentos referentes às concepções de Educação em Tempo Integral, destacamos que, atualmente, quando se busca implementar programas e/ou projetos com a ampliação da jornada escolar do educando, encontram-se disponíveis dois grandes formatos organizacionais, também, de acordo com Cavaliere (2009) denominados 'escola de tempo integral' e 'alunos em tempo integral'.

A primeira perspectiva (escola de tempo integral) tem um olhar voltado para a instituição escolar e o seu fortalecimento enquanto responsável pelo processo educativo de apropriação, por parte dos alunos, dos conhecimentos e saberes, socioistoricamente, construídos.

Por sua vez, a segunda perspectiva (alunos em tempo integral) se relaciona com a oferta aos educandos de experiências educativas através de outros educadores, inseridos em diferentes espaços sociais, conforme podemos perceber na citação que se segue:

No primeiro, a ênfase estaria no fortalecimento da unidade escolar, com mudanças em seu interior pela atribuição de novas tarefas, mais equipamentos e profissionais com formação diversificada, pretendendo propiciar a alunos e professores uma vivência institucional de outra ordem. 
No segundo, a ênfase estaria na oferta de atividades diversificadas aos alunos no turno alternativo ao da escola, fruto de articulação com instituições multissetoriais, utilizando espaços e agentes que não os da própria escola, pretendendo propiciar experiências múltiplas e não padronizadas. (CAVALIERE, 2009, p. 53)

Entretanto, independente de qual perspectiva de ampliação da jornada escolar seja adotada/ofertada aos alunos, temos a compreensão de que novas práticas educativas devem ser incorporadas na compreensão de que o aumento do tempo amplie, juntamente, as possibilidades de aprendizagem dos educandos e, neste contexto, venha a promover uma educação para uma formação humana mais completa - ou seja, uma Educação Integral.

Sendo assim, nas seções que se seguem abrimos um espaço para discutirmos sobre outras 'Pedagogias' para a materialização de uma Educação em Tempo Integral mais significativa. E, como esta orientação - de construção de novas 'Pedagogias' - veio do patrono da educação brasileira, trazemos, na seção 1, a partir das contribuições de Freire (1987 e 1996) uma discussão voltada para a Pedagogia do Oprimido e a Pedagogia da Autonomia.

\section{Pedagogia do Oprimido e Pedagogia da Autonomia}

Nesta seção, faz-se necessária a discussão de Freire sobre os saberes imprescindíveis a uma prática socioeducativa significativa, abordados anteriormente. Percebe-se a importância de trazer à discussão alguns de seus pressupostos abordados nas obras Pedagogia da Autonomia e Pedagogia do Oprimido, que, em 2018, completa 50 anos de sua elaboração, tendo em vista a possibilidade de novas formas de lidar com a diversidade, com os diferentes contextos e conflitos que constituem os sujeitos.

O livro a Pedagogia do Oprimido, de 1968, é uma das primeiras obras literárias a mostrar que aos oprimidos, nas sociedades latino-americanas, eram oferecidas esferas educativas e socioeducativas que mantinham um movimento de reforço das desigualdades. Num panorama social em que os sujeitos não são respeitados em suas diferenças e precisam se 'ajustar', ainda nesta contemporaneidade, Freire (1987) discute este movimento dentro das instituições de ensino. No campo teórico da Pedagogia Social no Brasil, no qual Paulo Freire é grande referência, percebemos a mesma dinâmica em contextos não escolares: um educador que transfere o conhecimento, deposita seus saberes, disciplina.

Não é de estranhar, pois, que nesta visão "bancária" da educação, os homens sejam vistos como seres da adaptação, do ajustamento. Quanto mais se exercitem os educandos no arquivamento dos depósitos que lhes são feitos, tanto menos desenvolverão em si a consciência crítica de que resultaria a sua inserção no mundo, como transformadores dele, como sujeitos. Quanto mais se lhes imponha passividade, tanto mais ingenuamente, em lugar de transformar, tendem a adaptar-se ao mundo, à realidade parcializada nos depósitos recebidos. (FREIRE, 1987, p. 34) 
A respeito da formação integral dos sujeitos, utilizando uma estratégia de ampliação da jornada, dificilmente, numa educação bancária, proporcionaremos acesso a diferentes saberes que podem favorecer a transformação de contextos sociais. Se num turno único, ou num contraturno, oferecermos mais do mesmo dessa educação que oprime, não dialoga, não emancipa, reforça desigualdades, como é possível fomentar transformações? Como é possível formar o sujeito integralmente, depositando um conhecimento engessado que, por vezes, reproduz preconceitos, desigualdades, com o objetivo de se manter tudo como está?

A mudança é importante. O movimento de se reinventar é necessário, como aconteceu com o próprio Freire, por ocasião da elaboração do livro Pedagogia da Esperança (FREIRE, 1921). Na referida obra, Paulo Freire pede atenção, às editoras, ao publicarem o livro Pedagogia do Oprimido, pois identifica nele uma linguagem machista.

Começarei exatamente pela linguagem machista que marca todo o livro e de minha dívida a um sem-número de mulheres norte-americanas que, de diferentes partes dos Estados Unidos, me escreveu, entre fins de 1970 e começos de 1971, alguns meses depois que saiu a primeira edição do livro em Nova York. Era como se elas tivessem combinado a remessa de suas cartas críticas que me foram chegando às mãos em Genebra durante dois a três meses, quase sem interrupção. (FREIRE, 1921, p. 34)

A reflexão sobre sua prática a torna significativa, na medida em que evitamos dinâmicas socioeducativas que favoreçam a opressão e, tão somente, a transmissão de conhecimento. $O$ diálogo contribui para a formação e a constituição dos sujeitos que estão, em determinado momento, na condição de educador e educando. O educador sai da posição de opressor, daquele que detém o conhecimento e incentiva a reflexão, a visão crítica da realidade proporcionada pela leitura do mundo, refletindo, também, sobre suas práticas em contextos escolares e não escolares. No entanto, pensar criticamente, na atualidade, ainda é perigoso (FREIRE, 1987). Identificar-se como oprimido gera a responsabilidade de fazer algum movimento para se emancipar. Identificarse como opressor, traz a mesma responsabilidade e exige mudanças.

A Pedagogia do Oprimido, portanto, "trata-se de uma concepção nascida nas experiências sociais e inseparável dos sujeitos dessas experiências como produtores de conhecimentos e reconstruída por esses mesmos sujeitos" (GADOTTI, 2016, p. 10).

Assim, Paulo Freire foi um educador que muito contribuiu para a construção de uma educação mais libertadora - aquela que percebe as diferenças entre as pessoas e não as utiliza como fundamento de discriminação e produção de mais desigualdade. Dessa forma, trazemos ainda, algumas considerações sobre a Pedagogia da Autonomia ampliando a reflexão sobre a materialização da Educação em Tempo Integral em solo brasileiro. 
A autonomia, enquanto amadurecimento do ser para si, é processo, é vir a ser. Não ocorre em data marcada. É neste sentido que uma pedagogia da autonomia tem de estar centrada em experiências estimuladoras da decisão e da responsabilidade, vale dizer, em experiências respeitosas da liberdade. (FREIRE, 1996, p. 107)

A escolha por essa obra, dentre tantas outras "Pedagogias" elaboradas por Freire, se alinha à perspectiva de que, nessa produção, o autor continua a discussão acerca dos diferentes "saberes necessários à prática educativa" em espaços escolares e não escolares.

A obra "Pedagogia da Autonomia", elaborada por Paulo Freire em 1996, apresenta 3 (três) campos de discussão, a saber: primeiro, não há docência sem discência; segundo, ensinar não é transferir conhecimento; e, terceiro, ensinar é uma especificidade humana.

Estas três vertentes nos trazem exigências para a materialização de uma educação com um viés mais libertador, tais quais: rigorosidade metodológica; pesquisa; respeito aos saberes dos educandos; criticidade; estética e ética; corporificação das palavras pelo exemplo; risco, aceitação do novo e rejeição de qualquer forma de discriminação; reflexão crítica sobre a prática; reconhecimento e assunção da identidade cultural; consciência do inacabamento; reconhecimento do ser condicionado; respeito à autonomia do educando; bom senso; humildade, tolerância e luta em defesa dos direitos dos educadores; apreensão da realidade; alegria e esperança; convicção de que a mudança é possível; curiosidade; segurança, competência profissional e generosidade; comprometimento; compreensão de que o ato de educar é uma forma de intervenção no mundo; liberdade e autoridade; tomada consciente de decisões; saber escutar; reconhecer que a educação é ideológica; disponibilidade para o diálogo e querer bem aos educandos (cf. FREIRE, 1996, p. 7 e 8).

Convém salientar que, frente a essas exigências, o educador vai desenvolvendo - na percepção de suas potencialidades e de suas incompletudes correlacionado com suas escolhas cotidianas - a necessária autonomia na prática educativa, pois, como nos afirma Freire (1996) "a autonomia vai se constituindo na experiência de várias, inúmeras decisões, que vão sendo tomadas" (p. 107).

Essas escolhas vão posicionando o educador a favor ou contra uma educação que privilegia a formação humana mais completa dos educandos, ou seja, uma Educação Integral - que no 'tempo integral' se configura imperioso associar.

A desconsideração total pela formação integral do ser humano, a sua redução a puro treino fortalece a maneira autoritária de falar de cima para baixo a que falta, por isso mesmo, a intenção de sua democratização no falar com. (FREIRE, 1996, p. 116)

$\mathrm{Na}$ contramão desta perspectiva de desconsideração da formação integral do sujeito, fazse necessário perceber a possibilidade de desenvolvimento desta 'autonomia' na convivência com 
o outro cotidianamente, traços que trazemos na próxima seção com a discussão sobre Pedagogia da Convivência de Xesús Jares (2008).

\title{
4. Pedagogia da Convivência
}

Ao consultarmos o minidicionário da língua portuguesa, encontramos para o verbete 'convivência' a seguinte definição: 1. "Ação ou efeito de conviver; convívio. 2. Trato diário" (XIMENES, 2000, p. 255).

Dando continuidade à pesquisa, no verbo 'conviver' é possível identificar a perspectiva de "Viver em comum, em graus variados de intimidade" (Ibid, p. 255). Esses significados podem nos direcionar para uma compreensão da convivência numa esfera do senso comum como sendo o ato de "estar com o outro".

No entanto, faz-se necessário questionar o que se faz no 'estar com o outro' e como se estabelecem esses vínculos. $\mathrm{Na}$ convivência com o outro, vamos construindo conhecimentos e estabelecendo espaços formativos. Por isso, direcionamos o nosso olhar sobre a convivência não como um simples contato, mas sim como uma Pedagogia.

\begin{abstract}
A Pedagogia da Convivência propõe reaprender a utilizar nossos espaços de interação para melhor compreender o outro e suas intenções. É necessário, para isso, uma ética do diálogo que estimule o questionamento, com liberdade, sinceridade e respeito mútuo, sem determinação institucional. Perguntar mobiliza quem questiona e quem formula a resposta. (GRACIANE, 2011, p. 96)
\end{abstract}

A partir das contribuições apresentadas, convém esclarecer que esta construção "Pedagogia da Convivência" foi criada pelo educador catalão Xesús Jares, no início do século $X X I$, enquanto uma forma de estruturação do trabalho educativo para espaços escolares perspectivando-se alcançar a educação a partir de dois pressupostos fundamentais: os direitos humanos e a vivência da paz em tempos difíceis.

Desse modo, Jares (2008) elencou princípios elementares para a construção de uma 'Pedagogia' que proporcionasse uma convivência entre os sujeitos da educação. Para isso, categorizou 3 (três) conteúdos básicos para o início do exercício da prática educativa que respeita os direitos humanos e a paz, a saber:

Conteúdos de natureza humana: direito à vida e ao desejo de viver, à dignidade, à felicidade, à esperança.

Conteúdos de relação: ternura, respeito, não violência, aceitação da diversidade e rejeição a qualquer forma de discriminação, solidariedade, igualdade.

Conteúdos de cidadania: justiça social e desenvolvimento, laicismo, estado de direito, direitos humanos. (cf. JARES, 2008, p. 29) 
Assim, observamos que, para além do "viver em comum", a Pedagogia da Convivência se nos apresenta enquanto uma possibilidade de prática pedagógica sistematizada e fundamentada na construção de valores considerados "universais" que contribuem para o fortalecimento da educação no campo social.

Conviver significa viver uns com os outros com base em certas relações sociais e códigos valorativos, forçosamente subjetivos, no marco de um determinado contexto social. Estes polos que marcam o tipo de convivência estão potencialmente cruzados por relações de conflito, o que de modo algum ameaça a convivência. Conflito e convivência são duas realidades sociais inerentes a toda forma de vida em sociedade. (JARES, 2008, p. 25)

Atualmente, podemos perceber o quanto a convivência com o outro está sendo comprometida - justamente pela estrutura de sociedade capitalista em que estamos inseridos na qual a forma de se relacionar com o outro vem sendo modificada, a adesão de aparelhos eletrônicos é potencializada e os laços humanos se encontram fragilizados, cotidianamente. O filósofo Bauman, discorre sobre este movimento. Ao apresentar uma de suas obras, destaca que,

O principal herói deste livro (Amor Líquido) é o relacionamento humano. Seus personagens centrais são homens e mulheres, nossos contemporâneos, desesperados por terem sido abandonados aos seus próprios sentidos e sentimentos facilmente descartáveis, ansiando pela segurança do convívio e pela mão amiga com que possam contar num momento de aflição, desesperados por "relacionar-se" e, no entanto, desconfiados da condição de "estar ligado" em particular de estar ligado "permanentemente" para não dizer eternamente, pois temem que tal condição possam trazer encargos e tensões que eles não se consideram aptos nem dispostos a suportar, e que podem limitar severamente a liberdade de que necessitam para _sim, seu palpite está certo _ relacionar-se. (BAUMAN, 2014, p. 6)

$\mathrm{Na}$ compreensão de Bauman (2004), estamos inseridos numa sociedade 'líquidomoderna' que vem produzindo seres egocêntricos, individualistas, adeptos ao consumo exacerbado e ao estabelecimento de relações por meio de interesses que contribui para o distanciamento entre as pessoas e a construção de processos de desigualdade social em diferentes espaços, como podemos observar junto às ponderações de Graciani (2011):

A negação do outro, diferente de mim, tem sido considerada, no mundo contemporâneo, um dos piores fatores geradores de conflitos sociais, dissabores pessoais, revoltas e agressões, entre outros. A invisibilidade do outro que está ao meu lado é um dos componentes do processo da exclusão, seja ela causada por preconceito étnico, cultural, religioso, por discriminação de gênero, opção sexual ou desigualdade social (p. 96). 
Esta realidade podemos encontrar, inclusive, nas unidades escolares, principalmente, nas que são de Educação em Tempo Integral, pois, ao aumentarem o tempo de permanência dos alunos na escola, os momentos de interação entre os educandos são potencializados para a existência de uma atuação pedagógica planejada e direcionada para uma educação em direitos humanos, que promova uma educação direcionada para a paz, dentro e fora da escola.

Quando os elementos apontados por Jares não são levados em consideração, pelos educadores sociais e professores, acredita-se que os vínculos humanos se fragilizam ainda mais e a convivência fica comprometida dificultando, assim, a promoção de uma educação, efetivamente, integral.

\section{Pedagogia da Hospitalidade}

Nesta terceira e última seção deste artigo, esboçamos algumas contribuições da educadora portuguesa Isabel Baptista (2012) na construção dessa reflexão necessária sobre a promoção de uma educação mais justa e solidária.

A partir da relação entre Ética e Educação Social, a autora repensa o valor da ética na prática profissional daqueles que trabalham com a educação social. Embora o seu foco principal seja para os educadores sociais portugueses, fazemos uma relação com a educação escolar em tempo integral levando em consideração que, por meio da ampliação do tempo do educando na escola, se tem a oportunidade/necessidade de se produzirem ações (socio)educativas que contribuam para a sua formação humana mais completa - Educação Integral.

Neste sentido, a estrutura social contemporânea, que apresentamos na Pedagogia da Convivência, é percebida como demanda na sua reflexão sobre Hospitalidade, e que buscamos entender como uma 'Pedagogia', pois sinaliza a necessidade da construção de um "laço social num mundo desenlaçado", por meio da "mediação socioeducativa" (cf. BAPTISTA, 2012, p. 38).

$\mathrm{Na}$ contramão desta sociedade produtora de fragilidades nas relações humanas, identificamos, na Ética da Hospitalidade ou, como queremos tratar, "Pedagogia da Hospitalidade", o desmembramento do valor ético em três grandes dimensões a serem trabalhadas pelos educadores:

Acolhimento: a hospitalidade define-se pela disposição para receber o hóspede de modo a que este se sinta em nossa casa como se estivesse em sua própria casa, pela disposição para aceitar que o Outro possa fazer lei no espaço de nossa autoridade.

Responsabilidade: ser responsável pelo Outro desta maneira não significa substituir o Outro na sua própria responsabilidade. Não podemos tomar o 
lugar que lhe pertence ou arrogarmo-nos o direito de cobrar o exercício dos seus próprios deveres.

Bondade: a bondade tempera o acolhimento e a responsabilidade como um sopro de bem ou subtil excesso da vontade que, ao mesmo tempo que faz transbordar toda a obrigação pessoal, profissional ou cívica, introduz elementos de delicadeza, moderação e serenidade. A bondade não é um acrescento, mas um fermento. (cf. BAPTISTA, 2012, p. 46-47)

A ética entendida e reorganizada a partir dessas três dimensões - tanto em espaços escolares quanto em ambientes não escolares - são consideravelmente relevantes, na medida em que contribuem para a construção de uma educação que tenha um compromisso com o outro e, por isso, materializa ações éticas e educativas cotidianamente.

Contudo, convém pontuar que a perspectiva ética, trazida pela autora, se direciona em uma tripla constituição: teleológica; deontológica e prudencial.

A ética é consubstanciada ao processo de afirmação identitária dos educadores sociais, mas só valorizando a ética profissional na sua tripla dimensão - teleológica, deontológica e prudencial - poderemos fazer justiça ao caráter distintivo da profissão, aqui interpretado à luz de uma 'ética da hospitalidade' assente no tríptico acolhimento, responsabilidade e bondade. (BAPTISTA, 2012, p. 39)

Ou seja, a partir da constituição do campo das finalidades para além do posto cotidianamente pelas relações sociais (teleológica), o comportamento em grupo tende a se humanizar-se nas relações educativas (deontológico) e, por isso, o campo das escolhas passa a ser uma relação direta com a capacidade de empatia pelo outro (prudencial).

Dessa forma, o que chamamos de "Pedagogia da Hospitalidade" contribui para a compreensão da necessidade de se produzir uma educação mais ampliada englobando uma formação multidimensional para os educandos, como entendemos a partir das contribuições de Coelho (2009).

Nesse sentido, é importante dizer que falar sobre educação integral, para nós, pressupõe falar, também, em tempo ampliado/integral na escola: com o tempo escolar ampliado, é possível pensar em uma educação que englobe formação e informação e que compreenda outras atividades - não somente as conhecidas como atividades escolares - para a construção da cidadania partícipe e responsável (p. 93).

Faz- se necessário aprofundarmos mais nas dimensões constituintes da ética da hospitalidade, porém já compreendemos que esta pode ser cunhada na perspectiva de fundamentar a prática socioeducativa dos educadores sociais - que, em sua maioria, trabalham em espaços não escolares ao mesmo tempo em que também podem auxiliar na crescente inserção destes educadores no contexto escolar - por meio da ampliação da 
jornada diária quando, numa perspectiva contemporânea de Educação Integral e(m) Tempo Integral, sujeitos de diferentes espaços formativos atuam para a dinamização deste trabalho.

\section{Considerações Finais}

Enfim, este artigo carrega algumas reflexões sobre possíveis 'Pedagogias' que podem contribuir para a formação integral dos sujeitos que permanecem em tempo integral, em contextos escolares e não escolares, sem perder de vista a centralidade da escola neste processo.

A Pedagogia do Oprimido nos leva a pensar sobre a importância do diálogo no movimento de ruptura dos mecanismos de opressão; sobre a importância da palavra que, aliada à prática, pode transformar. Em sua obra, Paulo Freire traz a importância do amor, da humildade, da fé nos homens, da esperança, do pensar crítico, da educação problematizadora, dialogando com os outros autores elencados nesta pesquisa para o estudo de outras 'Pedagogias'. Em sua reflexão na Pedagogia da Autonomia percebemos a necessidade de combater o autoritarismo, ainda presente em muitas instituições escolares e não escolares.

A Pedagogia da Convivência, de Xesús Jares, nos mostra a importância de organizar conteúdos mínimos e necessários para que os sujeitos interajam de forma a vivenciarem, nos ambientes educacionais, valores universais e promotores de relações pacíficas.

A ética ou 'Pedagogia' da Hospitalidade, de Isabel Baptista, aborda as possibilidades de construirmos relacionamento éticos a partir do acolhimento, bondade e responsabilidade com o Outro, o que trará consequências transformadoras nas relações sociais e nos processos de compreensão do que é ser humano na contemporaneidade.

Essas 'Pedagogias' trazem propostas significativas e necessárias para a formação dos sujeitos e promoção de uma sociedade melhor e mais justa para todos e todas. Sobretudo neste momento vivido na sociedade brasileira.

Assim, concordando com Freire, percebe-se que o movimento é não nos prendermos nos fundamentos da educação já postos, mas de criarmos 'Pedagogias' a partir de novas realidades socioeconômicas. Formar integralmente os sujeitos subsome-se à oferta de mais oportunidades educativas significativas. E, em meio à modernidade líquida que vivenciamos, na qual os laços humanos têm estado cada vez mais frágeis, identificamos que as propostas trazidas pelos autores podem contribuir para a formação humana mais completa possível dos sujeitos que se encontram em jornada ampliada, isto é, para a Educação Integral e(m) Tempo Integral. 


\section{Referências}

BAPTISTA, Isabel. Ética e Educação Social - interpelações de contemporaneidade. Revista Interuniversitaria. Sevilla, n. 19, p. 37-40, 2012.

BAUMAN, Zygmunt. Amor líquido: sobre a fragilidade dos laços humanos. Rio de Janeiro: Zahar, 2004.

BRASIL. Lei n 13.005, de 24 de junho de 2014. Aprova o Plano Nacional de Educação. Diário Oficial da União, Brasília, DF, 26 de jun. 2014.

CASTEL, Robert. A insegurança social: o que é ser protegido? Petrópolis: Vozes, 2005.

CAVALIERE, Ana Maria Vilela. Escolas de tempo integral versus alunos em tempo integral.

Em Aberto, Brasília, v.22, n. 80, p.51- 63, abr. 2009.

CAVALIERE, Ana Maria Vilela. Tempo de escola e qualidade na educação pública. Educ. Soc., Campinas, vol. 28, n. 100 - Especial, p. 1015-1035, out. 2007.

CAVALIERE, Ana Maria Vilela; COELHO, Lígia Martha Coimbra da Costa. (Orgs.). Pesquisas sobre educação integral e tempo integral: histórias, políticas e práticas. Curitiba: CRV, 2017.

COELHO, Lígia Martha Coimbra da Costa. História(s) da educação integral. Em Aberto, Brasília, v. 22, n. 80, p. 83-96, abr. 2009.

FRABBONI, Franco. La integración escuela-territorio. Hacia una ciudad educadora. In: VILLAR, Maria Belén Caballo. A cidade educadora: nova perspectiva de organização e intervenção municipal. Lisboa: Instituto Piaget, 2001.

FREIRE, Paulo. Pedagogia da autonomia: saberes necessários à prática educativa. São Paulo: Paz e Terra, 1996.

FREIRE, Paulo. Pedagogia da esperança. São Paulo: Paz e Terra, 1921.

FREIRE, Paulo. Pedagogia do oprimido. 23. ed. São Paulo: Paz e Terra, 1987.

GADOTTI, Moacir. Educação integral no Brasil: inovações em processo. São Paulo: Editora e Livraria do Instituto Paulo Freire, 2009.

GADOTTI, Moacir. Pedagogia do Oprimido: leitura de seus leitores e intérpretes. Acervo Moacir Gadotti, $2016 . \quad$ Disponível em: $<$ http://gadotti.org.br:8080/jspui/handle/123456789/427>. Acesso em 25 de dez de 2017.

GRACIANI, Maria Stela Santos. A formação do educador social e a Pedagogia da Convivência. In: RAMOS, Marcos Fadaneli; ROMAN, Artur. Educadores Sociais: a Importância da formação na implementação de tecnologias sociais. Brasília, DF: Fundação Banco do Brasil, 2001.

HARGREAVES, Andy. El tiempo y el espacio en el trabajo del profesor. Revista de Educación. Madri: Centro de Publicaciones Del Ministerio de Educación y Ciencia, n. 298, 1992. 
JARES, Xesús R. Pedagogia da Convivência. São Paulo: Palas Athenas, 2008.

LECLERC, Gesuína de Fátima Elias. MOLL, Jaqueline. Programa Mais Educação: avanços e desafios para uma estratégia indutora da educação integral em tempo integral. Educar em Revista, Curitiba: Editora UFPR, n. 45, p. 91-110, jul./set. 2012.

MAURícIO, Lúcia Velloso (Org.). Tempos e Espaços Escolares: experiências, políticas e debates no Brasil e no mundo. Rio de Janeiro: Ponteio: FAPERJ, 2014.

MAURíCIO, Lúcia Velloso. Políticas públicas, tempos, escola. In: COELHO, Lígia Martha C. da Costa. Educação integral em tempo integral: estudos e experiências em processo. Rio de Janeiro: FAPERJ, 2009.

MENEZES, Janaína S. S. Educação integral \& tempo integral na educação básica: da LDB ao PDE. In: COELHO, Lígia Martha C. da Costa. (Org.) Educação Integral em tempo integral: estudos e experiências em processo. Rio de Janeiro, DP et Alii, 2009.

PAIVA, Jacyara Silva. Caminhos do Educador Social no Brasil. São Paulo: Paco Editorial, 2015.

PEREYRA, A. Miguel. La jornada escolar en Europa. Cuadernos de Pedagogía. Barcelona: Editorial Fontalba, n. 206, September, 1992.

SIRINO, Marcio Bernardino. Projeto 'Roda do Abraço': prática pedagógica e $(\mathrm{m})$ tempo integral fortalecendo os laços humanos. In: CAVALIERE, Ana Maria Vilela; COELHO, Lígia Martha Coimbra da Costa. (Orgs.). Pesquisas sobre educação integral e tempo integral: histórias, políticas e práticas. Curitiba: CRV, 2017.

XIMENES, Sérgio. Minidicionário Ediouro da Língua Portuguesa. São Paulo: Ediouro, 2000. 